\title{
Living doll paper doll
}

'I returned and saw under the sun, that the race is not to the swift, nor the battle to the strong, neither yet bread to the wise, nor yet riches to men of understanding, nor yet favour to men of skill; but time and chance happeneth to them all.' Ecclesiastes 9.11.

'Living Doll' was an early hit by Cliff Richard. In it, he declared that what he wanted was a 'Crying, talking, sleeping, walking, living, doll' (This was a long time ago now, when 'doll' was a more allowable expression for a young female companion). On the basis of her being those things, he was 'going to do [his] best to please her.' Despite this patronising tone, he seemed to be actively interested in the possibility of her infinite variety. He would take a risk on her being out of sorts from time to time and that how she would be, from day to day, would depend on a number of factors. He could see that she had been different in the past and might change again in the future.

Very often, when doctors are talking to people about their Sickness they avoid consideration of their infinite variety if they can. They settle for a more static and reliable version of the human condition. Of course, they argue, what they want to do is to get to the meat of the matter, if there is any, as fast as possible. What is the problem? When were you last all right? When did it start? Where did it start and where has it been since? Show me where! These are all lovely questions and very useful if the issue is the usual one of a recent downturn in well-being from a usual state of being very-well-thank-you. Its usefulness is confirmed by the regularity with which the approach is vindicated in cases of twisted ankles, septicaemia, and Hashimoto's thyroiditis, matters that might be incidental to the life being lived. It is equally useful in the large number of instances where nothing very much of medical interest is conveyed by the patient or understood by the doctor. Doctors say they are making a diagnosis. What they are really seeking is the earliest possible closure of the issue. Difficulties arise when Sickness persists and repeatedly resists elucidation by this technique, which is really best for Paper Dolls.

A 'Paper Doll' was what 'The Inkspots' decided to settle for in their, earlier, popular vocal hit. Each of these melodious men thought they would 'Rather have a paper doll to call my own than any fickle-minded real live girl.' When they came 'home at night she would be waiting; she would be the truest doll in all the world.' Of course she would; her options were limited by the defining characteristics they preferred. Age cannot wither, nor custom stale such limited variety. In reality, when the doctor calls home at night, after Mummy looked in and 'found her like that', or when they finally get her to a clinic, what will be waiting to be seen is a person. The Person the doctor sees is the one who has, just at that very moment, arrived at just this point in their biography. The biography is infinitely varied and although normal human physiology might run like a paper blueprint, human lives do not. To be in touch, even remotely, with what is going on in the sort of Sicknesses seen in our clinics it is necessary to know the context in which it is happening. Knowing the biography provides some understanding of the dimensions of what are attributed otherwise to 'time and chance that happeneth to us all'.

Probably medical people divide as between those who prefer Paper, or Living, Dolls. There are many static aspects of medicine. Most clinical activity is dynamic so it behoves most doctors to know how to be in touch with their patients' context. Some of this is implicit in General Practice, where a doctor might have known the patient all their life, and their mother before them. Curiously, not much of what they know gets into their referral letters. All too often it does not appear in the clinic notes either. I conclude that it is not thought relevant or not enough to be worth the effort. I suggest that it is. It certainly is if the Sickness is likely to be chronic, or lifelong.

At the interface of neurology and psychiatry there are a number of such Sicknesses. Many of them emerge in childhood. It is always painful and threatening to have a sick child, but nowadays most children can get better again. But some parents and carers have to live through the story of a Sickness. They have to live with an enigma, even a disappointment, even an embarrassment. If the doctors do not know what their story is, how can they play a useful part in it? The biography began in the conceptual act and it is set in a context within the social structure. Look at the next thick set of notes. What is known about these Persons? Maybe an hour spent listening to who they really are and what they are experiencing might be better than one spent in the EEG department?

Science cannot work on unique instances so biography is usually the province of men and women of letters. Their accounts are partial in every sense yet what they convey speaks so clearly to us, about ourselves and others, that we must be reaching across the improbabilities with our super-computer brains to create new syntheses. The more we take real history of the real family and the context of their lives, the better our skill at understanding the Predicament of our patients and their families. I am satisfied that if this is not a part of the science of medicine it is an important aspect of its art.

\section{David C Taylor}

DOI: $10.1017 / \mathrm{S} 0012162204000593$ 